\title{
Detecting Ehlers-Danlos Syndrome Early in Life Is an Urgent Priority
}

\author{
Hamonet $\mathrm{C}^{1 *}$, Ducret $\mathrm{L}^{2}$ and Bahloul $\mathrm{H}^{3}$ \\ ${ }^{1}$ Department of medicine, University Paris-East-Creteil [UPEC] PRM, France \\ ${ }^{2}$ Department of Center of diagnosis ELLAsante, Paris \\ ${ }^{3}$ Department of Integrative medicine system, France
}

*Corresponding author: Hamonet C, Department of medicine, University Paris-East-Creteil [UPEC] PRM, France

\begin{abstract}
Ehlers-Danlos syndrome is a frequent hereditary disease that affects all the connective tissue and is transmitted to all the children of an affected person. A diagnosis is possible, from birth, or shortly thereafter, when observing a clubfoot, hip dislocation, intestinal intussusception, acute umbilical or inguinal parietal hernia, hemorrhages [cutaneous, oral, gastric, intestinal, nasal], persistent constipation, regurgitation and vomiting during bottle-feeding, or false roads. These symptoms are often the cause of false allegations of abuse with children withdrawal and wrongful parents or false accusations of Munchausen disease "by delegation" in a parent, the mother most often.
\end{abstract}

Keywords: Ehlers-Danlos; hereditary disease; early diagnosis; ecchymosis; fractures; children abuse; hypemobility

\section{Introduction}

Ehlers-Danlos syndrome is a frequent [1] hereditary disease that affects all the connective tissue and is transmitted to all the children of an affected person. It's ancient [2,3] description by Tschernogobow, Moscow, 1881 and Ehlers, Copenhagen, 1900 has undergone an important clinical and pathophysiological update for the last 20 years. A reliable diagnosis, made on clinical grounds alone, is now possible in the absence of a biological marker. It is characterized by tissue fragility, including bones, diffuse and generalized dysproprioception. Most doctors remain unaware of this condition, exposing children to iatrogenic accidents and parents to false accusations of child abuse [4]. This goes to show the importance of knowing how to carry out this diagnosis from the beginning of the child's life.

\section{Reminder of Diagnostic Criteria}

Confusion can be observed in the descriptions available to doctors and patients: new communication technologies allow everyone to have access to all information and to express, without control, all kinds of opinions. This situation is particularly devastating in Ehlers-Danlos disease, which has not been taught to doctors, and is expressed by mainly subjective signs, of which anxiety and imaginative creativity are part. Clinicians [5-9] have progressively regrouped, on large series of patients, clinical criteria which, by their singular association, allow the diagnosis: intense fatigue, diffuse pain, disruption of motor control by dysproprioception and dystonia, skin fragility, joint hypermobility, hemorrhage, hyperacusis, gastric reflux, autonomic dysfunction. These clinical signs' expression is variable evolving on a permanent background with episodes of crisis triggered by activity, trauma, hormonal factors (pregnancies, periods, menopause), climate change. Paucisymptomatic forms are identified by the presence in the family of a more complete clinical picture. The evolution, in the long term is very variable but an accentuation in adulthood is often observed.

Which signs should trigger an Ehlers-Danlos Syndrome diagnosis in a newborn or a very young child?

A diagnosis is possible, from birth, or shortly thereafter, when observing a clubfoot, hip dislocation, intestinal intussusception, acute umbilical or inguinal parietal hernia, hemorrhages (cutaneous, oral, gastric, intestinal, nasal), persistent constipation, regurgitation and vomiting during bottle-feeding, or false roads, intolerance to milk, very flexible joints, dislocated seats (shoulders, hips, finger knees) or joint crunches, particularly thin skin, irritable and easy to 
stretch, injury long or difficult to treat. Sometimes, frequent crying, evokes abdominal pain. Occurrence of "spontaneous fracture" for minimal trauma, epiphyseal or diaphyseal, costal but also cranial should suggest, before any other diagnosis, Ehlers-Danlos syndrome, because of its significant incidence which is estimated at $2 \%$ [1]. The cause may be low vitamin D level present in this pathology and possibly related to insufficiency of its manufacture by a pathological skin. Cerebral lesions can also be observed due to the lack of brain protection by pathological meninges and the shock waves' violence transmitted by overly lax tissues, as we have shown, with Professor Daniel Fredy with diffusion tensor MRI [10] (Figures 1-7).

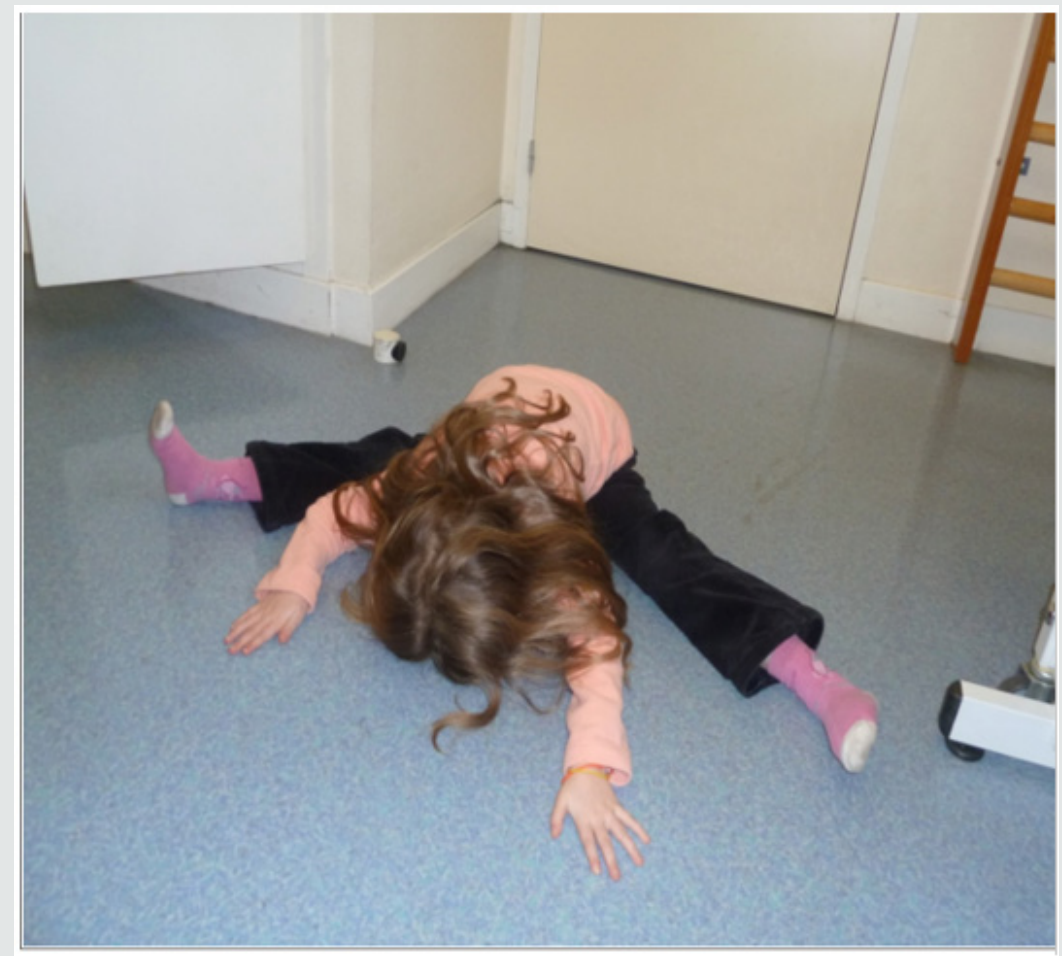

Figure 1: Young hypermobile girl

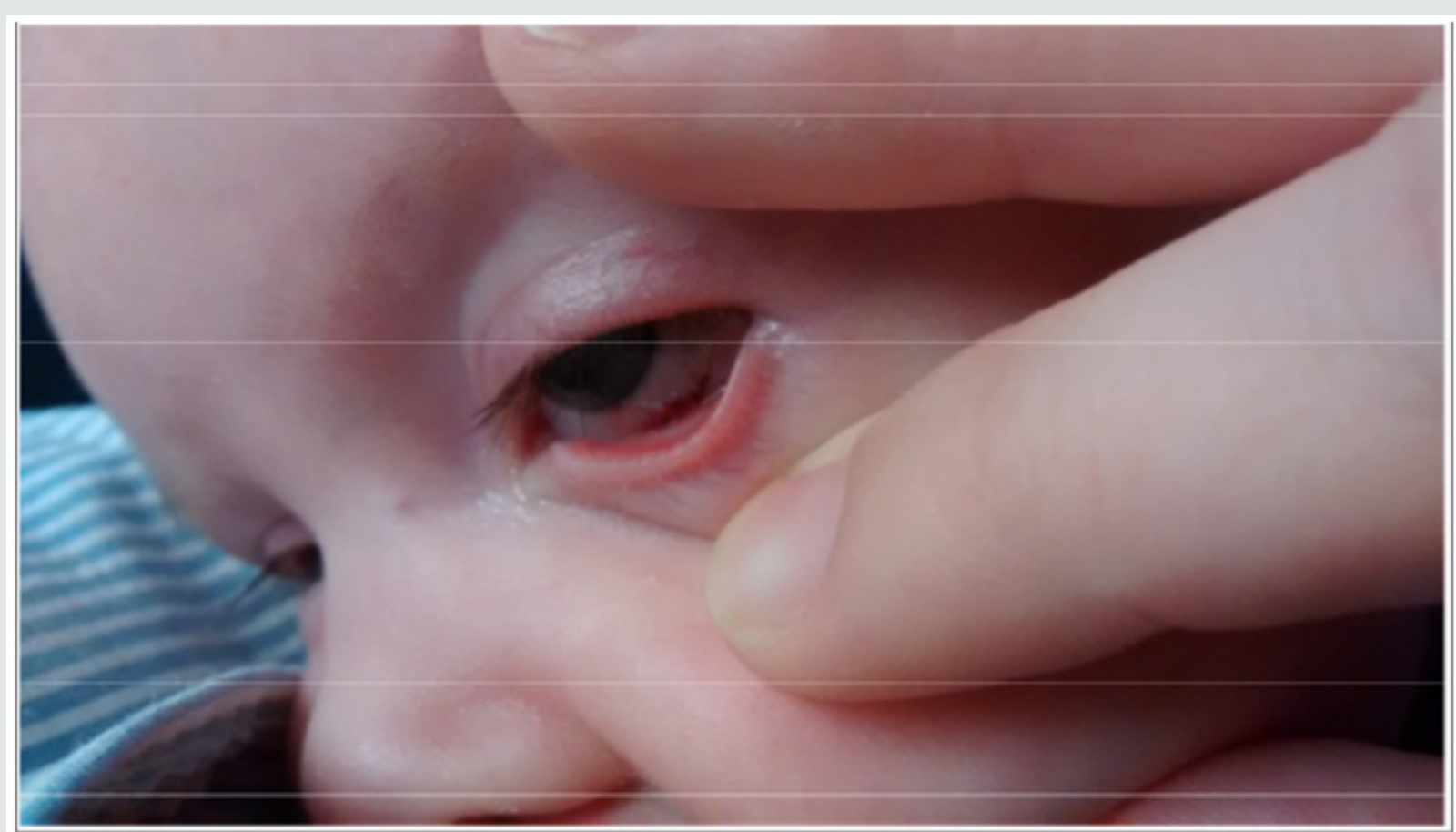

Figure 2: A 3-month-old baby with Conjunctival Hemorrhage 


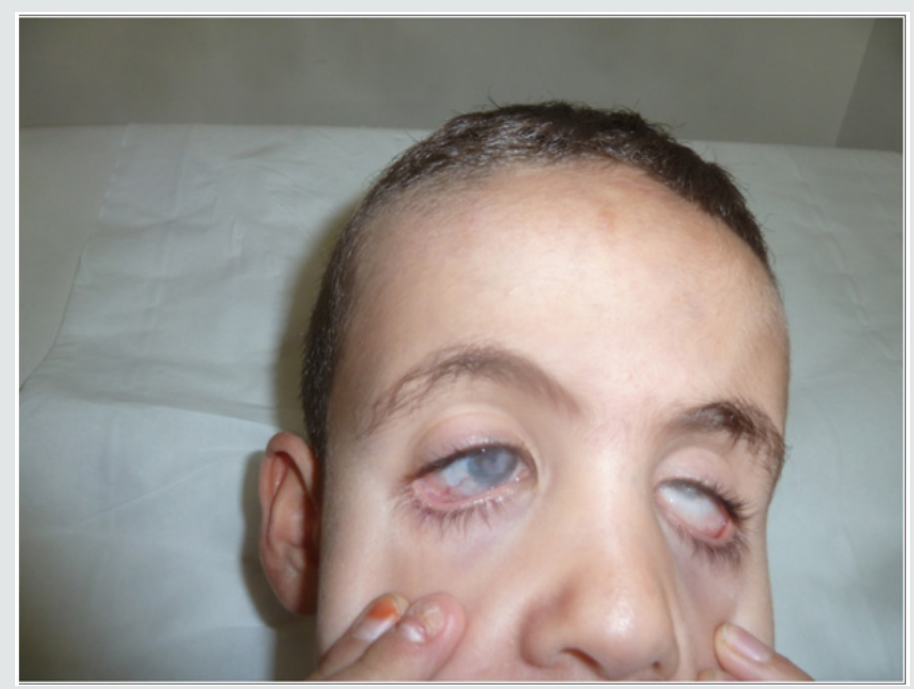

Figure 3: 12 years old boy with Ehlers-Danlos syndrome. Totally blind because of Sclerotic Necrosis of both eyes after Trauma and infection when he was Two years old

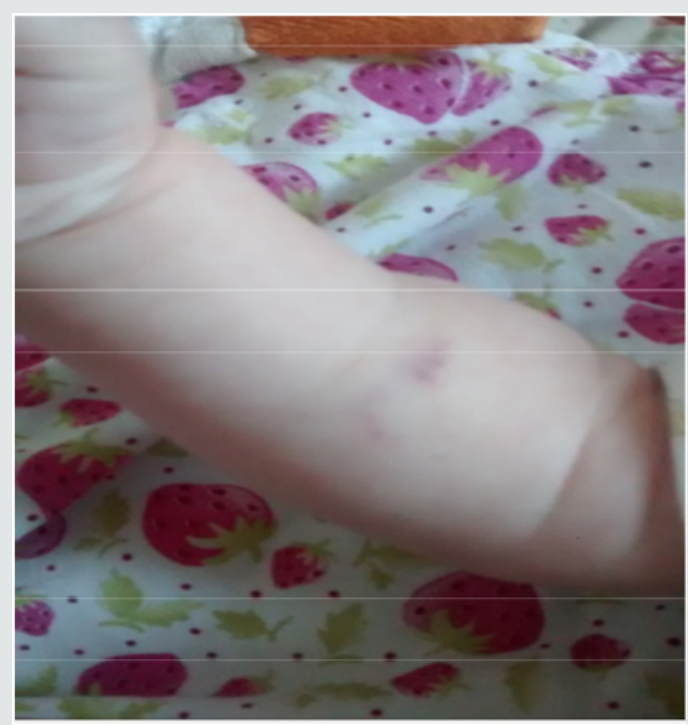

Figure 4: Ecchymosis in a 3-month-old baby whose mother is impacted by Ehlers-Danlos syndrome

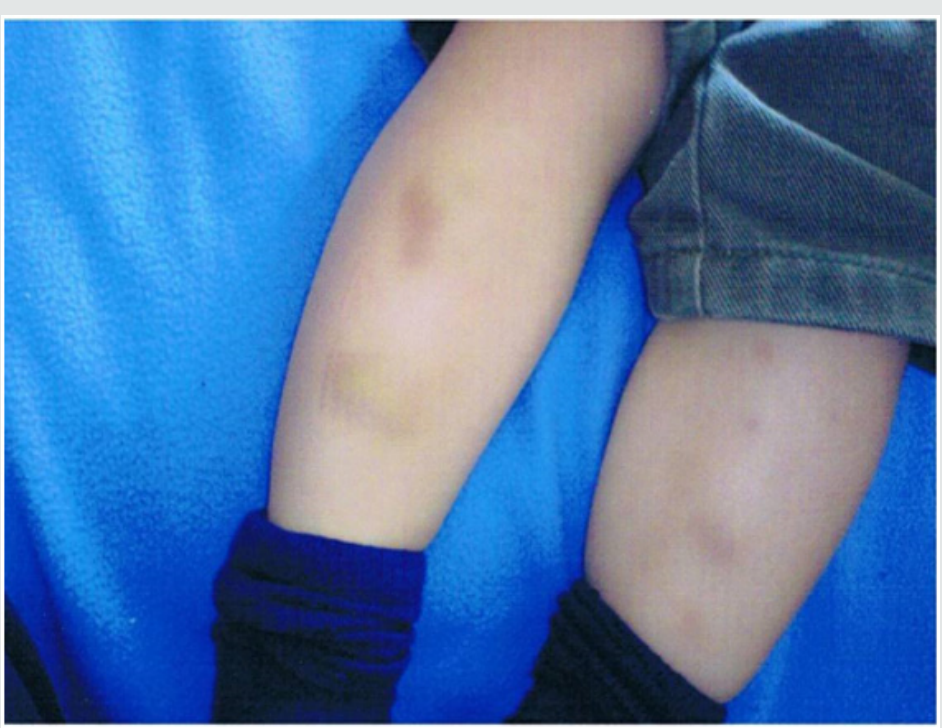

Figure 5: Leg ecchymosis in a young boy with Ehlers-Danlos syndrome 


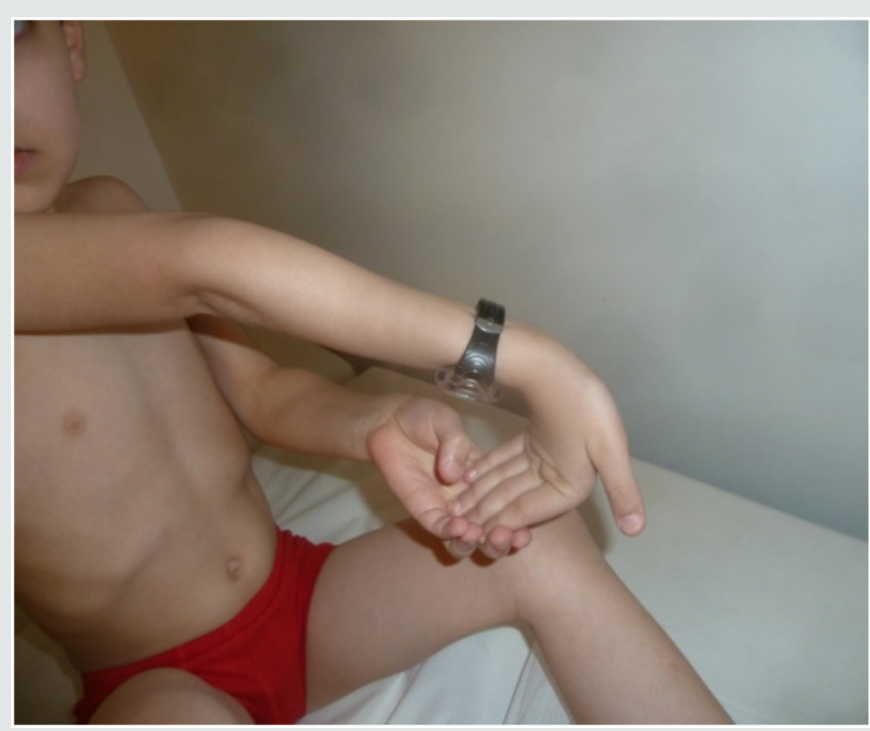

Figure 6: Upper limb joints Hypermobility.

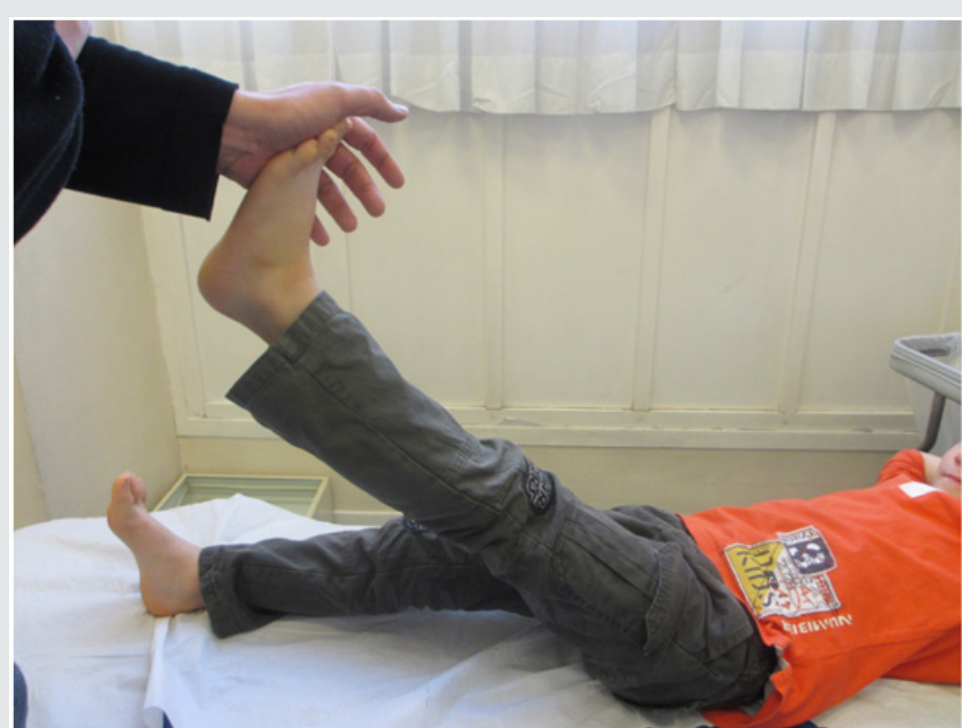

Figure 7: Knee's muscles retraction: a sign of Ehlers-Danlos syndrome.

Fractures, hematoma and cerebral lesions are often the cause of false allegations of abuse with children withdrawal and wrongful parents' convictions with psycho-emotional consequence. Serious adverse impact is also medical because of concerned children's lack of treatment. We must associate the false accusations of Munchausen disease "by delegation" in a parent, the mother most often [11].

\section{Conclusion}

Ehlers-Danlos is most likely, in the history of medicine, the disease that despite (or because of?) Its frequency estimated at $2 \%$ [1] remains the most ignored and is the cause of the greatest number of misdiagnosis. This is what Rodney Grahame [11] says when he writes: "It is incomprehensible that most doctors, specialized or not, do not detect it, do not know how to diagnose it, or, of course, how to treat it. Many, even, deny its existence, often causing the patient and his family dramatic and unnecessary suffering." The decisive diagnostic argument is brought by the demonstration of clinical signs of certainty in one of the parents, since this disease is systematically transmitted to all children. They must be searched consistently whenever one or more of the guidance signs are discovered, especially if parental abuse is suspected.

\section{References}

1. Tinkle B, Castori M, Berglund B, Cohen H, Grahame R, et al. (2017) Hypermobile Ehlers-Danlos Syndrome: Clinical description and natural history. Am J Med Genet Part C Semin Med Genet 175(1): 48-69.

2. Tschernogobow N A (1892) über einen Fall von Cutis Lockering laxa first meeting of Moscow Dermatologic and venerologic society. Monatshefte für paraktsche Dermatologie, Hamburg, 14: 76.

3. Ehlers E. Cutis laxa, Neigung zu Haememorragien in der Haut, lockering mehrerer Articulationen, Dermatologissche Zeitschrift.

4. Holick MF, Hossein-Nezhad, Tabatabaei F (2017) multiple fractures in infants who have Ehlers-Danlos/hypermobility syndrome and or vitamine D deficieciency. A case series of 72 infans whose parents were accused of child abuse and neglect. DermatoEndicrinology 9(17). 
5. Grahame R, Bird HA, Child A (2000) The revised (Brighton 1998) criteria for thr diagnosis of benign joint hypermobilty syndrome (BJHS). J Rheumatology 27: 1777-1779.

6. Hamonet C, Ravaud PH (2012) (all Ehlers-Danlos about 664 cases) Statistical analysis of clinical signs from 644 patients with a Beighton scale $>4 / 9$. First international Symposium on the Ehlers-Danlos syndrome. September 8-9 Ghent.

7. Chopra P, Tinkle B, Hamonet C, Brock I, Gompel A, et al. (2017) Pain management in the Ehlers-Danlos syndromes. American Journal of Medical Genetics, Part C Seminars in Medical Genetics 175(1).
8. Marino Lamari N (2017) Systemic Manifestations of Ehlers-Danlos Syndrome Hypermobility Type. MOJ Cell Science \& Report 4(2): 9-13.

9. Hamonet C, Frédy D, Lefèvre J H, Bourgeois Gironde S, Zeitoun J D (2016) Brain injury unmasking Ehlers-Danlos syndromes after trauma: The fiber print. Orphanet Journal of Rare Diseases 11: 45

10. Hamonet C, Jouvencel M, Manicourt D, Holick M (2019) Ehlers-Danlos et fausses accusations de maltraitances. Gaz. Pal. 5 mars, n GPL343y8, p. 19

11. Hamonet C, Ehlers-Danlos (2018) The disease forgetten by medicine, l'Harmattan.

\section{(C) \\ This work is licensed under Creative Commons Attribution 4.0 License}

To Submit Your Article Click Here:

Submit Article

DOI: 10.32474/PAPN.2019.02.000139

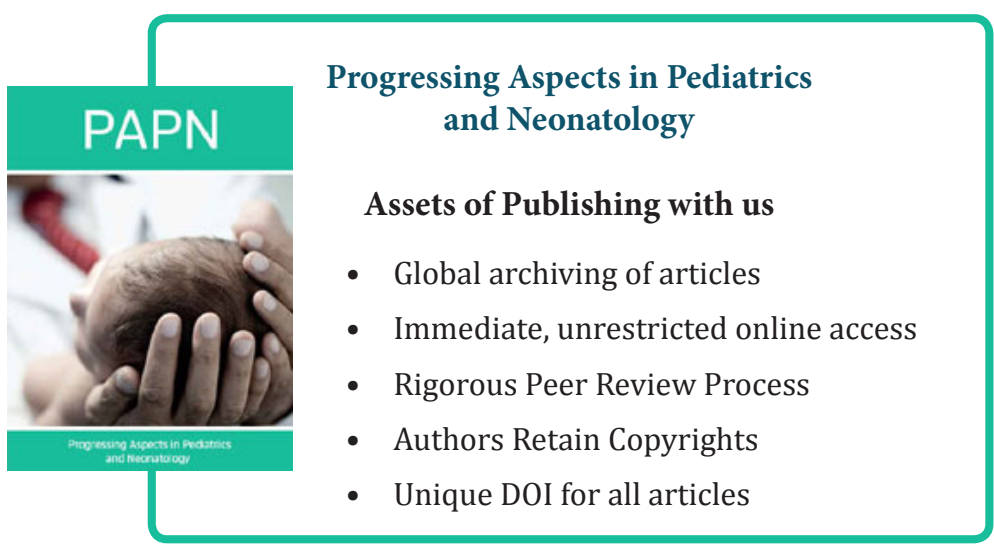

